\title{
Thermal/Photo Conversion of Silver 4-Nitrobenzoate to Nitro/Amine-Terminated
}

Ag Nanoparticles

Yeoung Uk Seo, Seung Joon Lee, and Kwan Kim*

Laboratory of Intelligent Interfaces, School of Chemistry and Molecular Engineering,

Seoul National University, Seoul 151-742, Korea

\section{Supporting Information}

\section{Room Temperature DRIFT spectrum of Silver 4-Nitrobenzoate}

Figure S1(a) shows the DRIFT spectrum of Ag-4NBA at room temperature. For comparison, in Figure S1(b) is shown the DRIFT spectrum of pure 4-NBA. In both spectra, the symmetric and the antisymmetric stretching peaks of the $\mathrm{NO}_{2}$ group appear distinctly at 1350 and $1515 \mathrm{~cm}^{-1}$, respectively. On the other hand, the symmetric and antisymmetric stretching peaks of the carboxylate group, i.e., $v_{\mathrm{s}}\left(\mathrm{COO}^{-}\right)$and $v_{\text {as }}\left(\mathrm{COO}^{-}\right)$, are clearly identified at 1387 and $1576 \mathrm{~cm}^{-1}$, respectively, in Figure S1(a). However, the carbonyl stretching peak $(\mathrm{v}(\mathrm{C}=\mathrm{O}))$, the hydroxyl stretching peak $(\mathrm{v}(\mathrm{C}-\mathrm{OH}))$, and the hydroxyl bending peak $(\delta(\mathrm{C}-\mathrm{OH}))$ appearing, respectively, at $\sim 1700,1294$, and $935 \mathrm{~cm}^{-1}$ in Figure S1(b) are completely absent in Figure S1(a), indicating that the as-prepared Ag-4NBA is not contaminated with free acid.

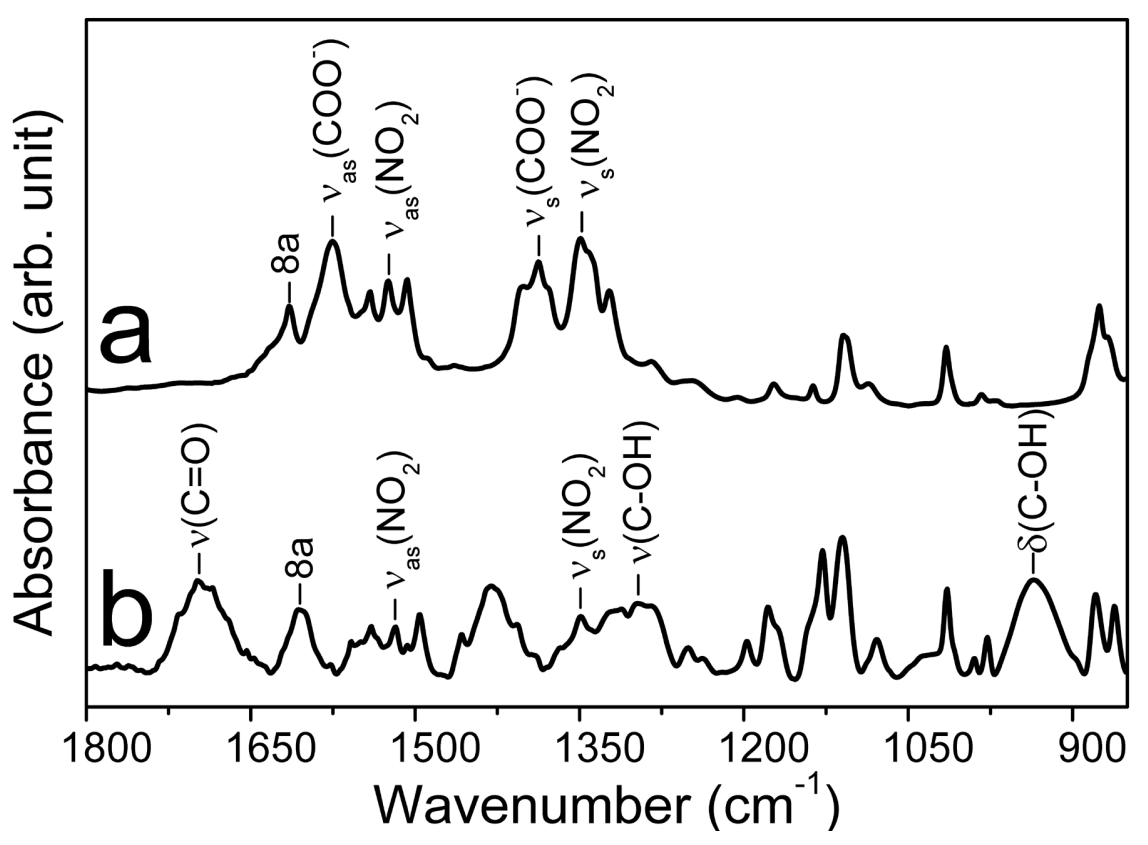

Figure S1. DRIFT spectra of (a) silver 4-nitrobenzoate and (b) pure 4-nitrobenzoic acid. 


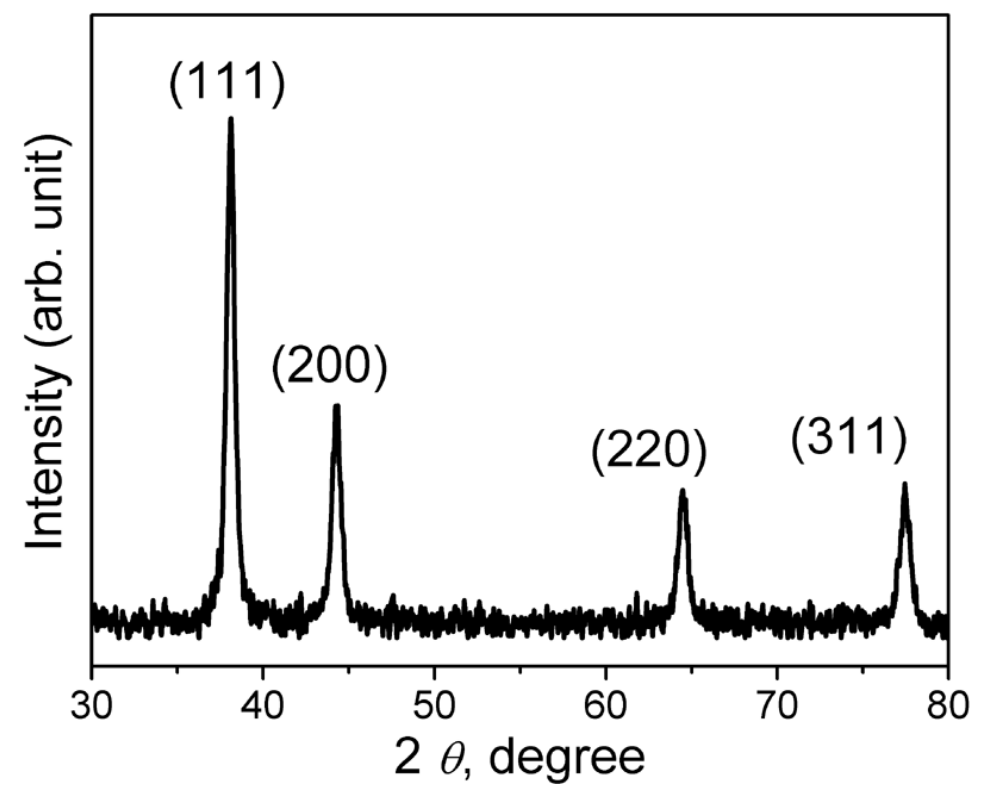

Figure S2. XRD pattern of silver nanoparticles obtained from the thermal decomposition of silver 4-nitrobenzoate. All the XRD peaks can be attributed to the reflections of face-centered cubic Ag. ${ }^{\text {S1 }}$

Reference

(S1) JCPDS ICDD PDF No. 02-1098, 03-0921, 03-0931. 